\title{
OPTIMALISASI KINERJA PERSEDIAAN SUKU CADANG UNTUK PELAKSANAAN MAINTENANCE REPAIR OVERHAUL (MRO) DENGAN PENERAPAN COMPUTERIZED MAINTENANCE MANAGEMENT SYSTEMS (CMMS) (Studi Kasus di PT. Indonesia Asahan Aluminium)
}

\author{
Sutrisno, Gunawan MP., Raymond PT. \\ Program Studi Teknik Industri, Fakultas Teknologi Industri \\ Universitas Pembangunan Nasional "Veteran" Yogyakarta \\ Jalan Babarsari No 2 Tambakbayan Yogyakarta \\ email : $\underline{\text { Jur tiupn@telkom.net }}$
}

\begin{abstract}
PT.Inalum is a manufacturing company engaged in the aluminum smelting industry. PT.Inalum pengendaliaan system requires an inventory of spare parts to conduct maintenance, repair and overhaul (MRO). CMMS (Computerized Maintenance Management System) is a computerized maintenance system running on a LAN (Local Area Network). CMMS is influenced by three variables, namely an integrated maintenance, inventory and procurement so as to create a good maintenance should be supported by the inventory control of spare parts used in maintenance. CMMS aims to make the work more efficient and effective, especially in matters relating to maintenance. That as a benchmark to measure the performance of CMMs for spare parts inventory control is a key performance indicator (KPI). This study aims to evaluate and compare key performance indicators before and after implementation of CMMS for the implementation of MRO activities. Another goal to be achieved is to determine the factors that affect the value of the inventory of spare parts. Based on the results of data processing and analysis can be seen that by looking at a comparison of before and after implementation of CMMS on key performance indicators, it appears that there is an improvement in every parameter, one of which is the value of the inventory prior to the implementation of CMMS for $\$$ $34,790,000.00$ compared to after the application of the inventory value fell to $\$ 19,632,000.00$. Factors that affect the value of the inventory is the inventory of spare parts, maintenance, procurement, and human resources.
\end{abstract}

\section{Keywords: Performance CMMS, Key Performance Indicators, Value Inventory}

PT.Inalum merupakan perusahaan manufaktur yang bergerak dalam bidang industri peleburan aluminium. PT.Inalum membutuhkan suatu sistem pengendaliaan persediaan suku cadang untuk melakukan kegiatan maintenance, repair and overhaul (MRO). CMMS (Computerized Maintenance Management System) merupakan sistem pemeliharaan secara komputerisasi yang dijalankan pada jaringan LAN (Local Area Network). CMMS dipengaruhi oleh tiga variabel yang saling terintegrasi yaitu pemeliharaan, persediaan dan pengadaan sehingga untuk menciptakan suatu pemeliharaan yang baik harus didukung oleh pengendalian persediaan terhadap suku cadang yang digunakan dalam pemeliharaan. CMMS bertujuan untuk membuat pekerjaan lebih efisien dan efektif terutama dalam hal-hal yang menyangkut pemeliharaan. Yang menjadi tolak ukur dalam mengukur performansi CMMS untuk pengendalian persediaan suku cadang adalah key performance indicator (KPI). Penelitian ini bertujuan untuk mengevaluasi dan membandingkan key performance indicator sebelum dan setelah penerapan CMMS untuk pelaksanaan kegiatan MRO. Tujuan lain yang ingin dicapai adalah untuk mengetahui faktor-faktor yang mempengaruhi nilai persediaan suku cadang. Berdasarkan hasil pengolahan data dan analisis dapat dilihat bahwa dengan melihat perbandingan dari sebelum dan setelah penerapan CMMS pada key performance indicator, terlihat bahwa terdapat perbaikan dalam setiap parameter, salah satunya adalah nilai persediaan sebelum penerapan CMMS sebesar $\$ 34,790,000.00$ bila dibandingkan dengan setelah penerapan nilai persediaan turun menjadi $\$ 19,632,000.00$. Faktor-faktor yang mempengaruhi nilai persediaan suku cadang adalah persediaan, pemeliharaan, pengadaan, dan sumber daya manusia.

Kata kunci : Performansi CMMS, Key Performance Indicator, Nilai Persediaan 


\section{PENDAHULUAN}

Persediaan merupakan sejumlah barang yang disimpan untuk diproses lebih lanjut, dimana proses lebih lanjut tersebut adalah kegiatan proses produksi. Pengertian persediaan tidak hanya terbatas pada persediaan bahan baku atau produk jadi saja tetapi juga bisa berupa keahlian yang sewaktu-waktu dapat digunakan untuk memenuhi kebutuhan-kebutuhan yang akan datang. Persediaan yang dikatakan baik adalah suatu kondisi dimana besar atau jumlah persediaan itu terpenuhi untuk dapat menjamin kelancaran proses produksi.

Pengendalian persediaan merupakan suatu karakteristik dasar dari industri modern, sebab pada dasarnya pengendalian yang efektif atas faktor-faktor seperti manusia, bahan, mesin, dan uang akan ke arah perolehan laba yang begitu penting dalam suatu perusahaan. Sejalan dengan semakin ketatnya persaingan pada industri manufaktur menuntut suatu perusahaan perlunya menerapkan pengendalian produksi terhadap persediaan. Karena pengendaliaan persediaan dalam suatu perusahaan memegang peranan penting untuk menunjang keberhasilan perusahaan tersebut, sehingga dengan adanya suatu pengendalian persediaan yang efektif dan efisien akan menjamin kelancaran proses produksi.

CMMS (Computerized Maintenance Management System) merupakan perangkat lunak yang dibangun berdasarkan suatu kondisi penerapan proses dan prosedur yang dinilai terbaik secara rata-rata di dunia yang telah dilakukan sejak konsep pemeliharaan dibangun sehingga apa yang terbaik di dalam dunia pemeliharaan coba diangkat dan diintegrasikan ke dalam perangkat lunak ini. Dengan kata lain CMMS merupakan suatu sistem pemeliharaan yang terkomputerisasi. Sistem ini secara garis besar terdiri dari tiga fungsi yaitu fungsi pemeliharaan, persediaan dan pengadaan. Ketiga fungsi ini diintegrasikan untuk mengoptimalkan sistem pemeliharaan yaitu dengan meningkatkan efisiensi diketiga bagian tersebut.

PT.INALUM (Indonesia Asahan Aluminium) merupakan suatu perusahaan manufaktur yang bergerak dalam bidang industri peleburan aluminium. Selama ini manajemen di PT.INALUM sering sekali dihadapkan dengan masalah-masalah pengendalian persediaan suku cadang untuk melakukan MRO (Maintenance Repair Overhaul). Adapun masalah-masalah yang dihadapi yaitu sering terjadi keterlambatan dalam pelaksanaan kegiatan MRO yang disebabkan tidak adanya suku cadang cadangan yang tersimpan di gudang, banyaknya duplikasi setiap suku cadang yang mengakibatkan terjadinya penumpukan kebutuhan suku cadang yang sama di setiap gudang. Dengan adanya permasalahan ini maka nilai persediaan di PT.INALUM setiap tahunnya meningkat terus.

Dengan nilai persediaan yang terus meningkat inilah yang membuat pihak manajemen mulai melakukan langkah-langkah untuk memperbaiki sistem pengendalian persediaan yang ada. Beberapa langkah yang dilakukan yaitu menerapkan suatu sistem CMMS dalam pengendalian persediaan suku cadang untuk pelaksanaan MRO.

\section{METODOLOGI PENELITIAN}

\subsection{Objek Penelitian}

Yang menjadi objek dalam penelitian ini adalah performansi CMMS dalam pengendalian suku cadang untuk kegiatan MRO di PT.INALUM.

\subsection{Teknik pengumpulan data}

Untuk mendapatkan hasil yang memuaskan tentang gambaran suatu persoalan dalam suatu penelitian, diperlukan pengumpulan data-data. Berdasarkan macamnya data dibagi menjadi 2 yaitu:

1.Data primer

Data primer didapatkan peneliti melalui wawancara dengan pihak PT INALUM.

2.Data Sekunder

Data ini antara lain permintaan jumlah suku cadang, jumlah persediaan suku cadang, biaya yang dikeluarkan, data inactive inventory, dan data jumlah permintaan tambahan suku cadang.

Ada beberapa tahapan pengumpulan data diantaranya adalah sebagai berikut:

a. Observasi merupakan metode pengumpulan data secara langsung pada obyek yang diteliti,

b. Interview merupakan metode pengumpulan data dengan cara tanya jawab langsung kepada pihak perusahaan yang terkait secara sistematis dan berdasarkan pada tujuan penelitian.

\subsection{Langkah-langkah Pengolahan Data}

Langkah-langkah dalam pengolahan data sebagai berikut: 
1. Perhitungan Nilai Persediaan

Nilai persediaan merupakan salah satu parameter dalam menilai kinerja persediaan. Data yang dibutuhkan dalam perhitungan nilai persediaan ini adalah jumlah suku cadang yang digunakan untuk melakukan kegiatan MRO dan harga suku cadang per item. Nilai persediaan yang dikatakan baik apabila nilai persediaan tersebut berada pada level yang optimal.

2. Perhitungan Level Of Service

Level of service merupakan tingkat pelayanan terhadap permintaan suku cadang oleh bagian pemeliharaan. Dalam melakukan perhitungan level of service membutuhkan hasil perhitungan dari tingkat penggunaan atau konsumsi $(C p)$ dan hasil perhitungan dari tingkat penggisian $(F p)$.

Adapum rumus yang digunakan dalam melakukan perhitungan LOS adalah :

$$
\text { LOS }=(\Sigma(C p \times F p)) \times 100 \%
$$

$C p$ merupakan tingkat penggunaan suku cadang untuk melakukan MRO. Dalam melakukan perhitungan $C p$ data yang dibutuhkan adalah data total konsumsi suku cadang dan data konsumsi suku cadang per item.

Adapun rumus yang digunakan dalam melakukan perhitungan $C p$ adalah sebagai berikut :

$$
C p=\underline{\text { konsumsi untuk item } \mathrm{p}}
$$

Konsumsi total

$F p$ merupakan tingkat permintaan suku cadang untuk melakukan MRO. Dalam melakukan perhitungan $F p$, data yang dibutuhkan adalah data jumlah permintaan suku cadang dan data jumlah permintaan suku cadang yang terpenuhi.

Adapun rumus yang digunakan dalam melakukan perhitungan $F p$ adalah sebagai berikut :

$$
F p=\frac{\text { Jumlah Permintaaan Suku Cadang }}{\text { Jumlah Suku Cadang Yang Terpenuhi }}
$$

Tujuan melakukan perhitungan level of service adalah untuk mengetahui ketersediaan suku cadang digudang untuk setiap barang dari pemeliharaan. Dan apabila levelnya bisa sampai pada kisaran 95\% - 97\% akan menjamin tidak adanya keterlambatan dalam melakukan pemeliharaan.

3. Perhitungan Stock Level

Perhitungan stock level (S) ini bertujuan untuk mengetahui jumlah persediaan suku cadang yang digunakan dalam pelaksaan MRO. dalam melakukan perhitungan service ini membutuhkan data jumlah permintaan suku cadang, data jumlah permintaan suku cadang yang terpenuhi dan data jumlah permintaan tambahan suku cadang.

Adapun rumus yang digunakan dalam melakukan perhitungan stock level adalah sebagai berikut :

$$
S=O H+D I-B O
$$

Dimana :

$\mathrm{OH}=$ Jumlah permintaan suku cadang (Unit)

$D I=$ Jumlah permintaan tambahan suku cadang untuk perbaikan (Unit)

$B O=$ jumlah permintaan yang terpenuhi (Unit)

4. Perhitungan Turn Over Ratio

Perhitungan turn over ratio bertujuan untuk mengetahui perputaran pemakaian persediaan suku cadang yang ada digudang untuk kegiatan MRO. Dalam melakukan perhitungan turn over ratio data-data yang dibutuhkan adalah data nilai persediaan dan data tentang biaya yang dkeluarkan gudang untuk melakukan MRO.

Adapun rumus yang digunakan dalam melakukan perhitungan turn over ratio adalah sebagai berikut :

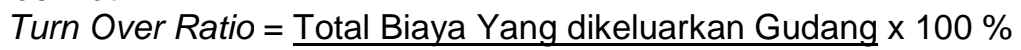

$$
\text { Total Nilai Persediaan }
$$

Apabila persentase turn over ratio bisa mencapai 95\% - 97\% maka jangka waktu persediaan suku cadang yang tersimpan di gudang semakin pendek. Sehingga secara langsung memberikan pengaruh terhadap penurunan nilai persediaan.

5. Perhitungan Sleeping Stock Ratio

Sleeping stock ratio merupakan suku cadang yang tidak aktif. dalam melakukan perhitungan sleeping stock ratio membutuhkan data jumlah permintaan suku cadang dan data jumlah permintaan suku cadang yang tidak aktif.

Adapun rumus yang digunakan dalam melakukan perhitungan sleeping stock ratio adalah sebagai berikut : 
Sleeping Stock Ratio = jumlah suku cadang yang tidak aktif $\times 100 \%$ total jumlah suku cadang

Dalam hal ini apabila persentase sleeping stock ratio bisa mencapai $1 \%$ secara tidak langsung akan mempengaruhi penurunan dari nilai persediaan.

\section{PENGOLAHAN DATA DAN ANALISA HASIL}

\subsection{Karakteristik sistem}

PT. Inalum adalah sebuah perusahaan yang bergerak dibidang produksi yaitu memproduksi aluminium. Untuk melakukan kegiatan MRO PT. Inalum membutuhkan suku cadang dari berbagai mesin-mesin yang digunakan di PT.Inalum. Penyampaian informasi dalam hal melakukan kegiatan MRO pertama kali dilakukan secara manual sehingga untuk melakukan kegiatan MRO departemen-departemen yang terkait dalam melakukan kegiatan MRO saling menunggu informasi dari departemen yang satu dengan departemen yang lain sehingga hal ini dapat mengganggu jalannya jadwal pemeliharaan dan jalannya proses produksi. Dalam hal ini PT.Inalum membutuhkan suatu pengendalian persediaan suku cadang yang dapat mengendalikan seluruh persediaan suku cadang yang dibutuhkan untuk melakukan kegiatan MRO.

Sehubungan dengan hal ini PT.Inalum membutuhkan suatu sistem yang dapat mengendalikan persediaan suku cadang. Untuk itu, PT.Inalum menggunakan CMMS yang berkaitan dengan pengendalian suku cadang untuk melakukan MRO. CMMS merupakan sistem pemeliharaan secara komputerisasi yang dijalankan pada jaringan LAN (Local Area Network) dengan beberapa komputer server yang terintegrasi menjadi satu dan sejumlah komputer client yang terhubung langsung dengan komputer server. CMMS dipengaruhi oleh tiga variabel yang saling terintegrasi yaitu pemeliharaan peralatan, sistem pergudangan atau persediaan dan pengadaan. Untuk menjalankan peran utama dari CMMS tersebut harus didukung oleh fungsi persediaan dalam hal kebutuhan material yang digunakan untuk melakukan kegiatan MRO. Material untuk pemeliharaan baik dalam bentuk suku cadang sangat berpengaruh terhadap tingkat efisiensi dan efektifitas dari sistem pemeliharaan. Adapun fasilitas-fasilitas yang diberikan CMMS yaitu, pertama memberikan kemungkinan untuk melakukan recording yang terperinci secara teknis dan terorganisir dengan baik sesuai dengan fungsi masing-masing peralatan, yang dikaitkan dengan suku cadang yang dibutuhkan oleh peralatan tersebut, termasuk di dalamnya orang yang melakukan kegiatan MRO tersebut. Kedua, sebagai management terhadap segala kegiatan maintenance. Sistem ini mendayagunakan komputasi (data base sistem) untuk melakukan management aktifitas maintenance asset organisasi. Untuk itu hal pertama yang dilakukan untuk menerapkan CMMS adalah standarisasi sistem registrasi asset mulai dari asset sistem service (misalnya kompresor service unit, power generation unit), equipment unit, maintainable unit sampai spare part. Selain itu asset man power resources (SDM) juga tercantum dalam data base CMMS. Kemudian setelah itu adalah sistem management pekerjaan yang biasanya berupa work order flow process yang mengatur bagaimana suatu alur pekerjaan maintenance harus dijadwalkan, direncanakan ataupun pembatalannya sekalipun dalam CMMS, sehingga pekerjaan maintenance dapat diatur dengan baik. Work order flow biasanya juga dilengkapi dengan Standar Operating Procedure atau sejenisnya sebagai petunjuk untuk melakukan pekerjaan dalam suatu work order. Dalam SOP itu biasanya dicantumkan special tool yang dibutuhkan, jenis human resources nya, perkiraan man hour, spare part yang diperlukan, consumable item dll. Dengan menggunakan data-data tersebut maka diharapkan pekerjaan maintenance dapat diatur, direncanakan dan dijadwalkan dengan baik serta CMMS pada umumnya adalah integrasi dari pada berbagai sistem seperti Work Order management, detail Equipment database, Preventive Maintenance (Inspection, Lubrication, Calibration, Cleaning, dll), Spareparts inventory dan Purchasing yg biasanya link dengan Finance untuk Invoice matching. Dari fasilitas-fasilitas yang berikan dapat disimpulkan peran utama dari CMMS ini adalah untuk menunjang dalam efektifitas suatu pelaksanaan pemeliharaan.

Oleh karena untuk mengukur keberhasilan CMMS dalam mengendalikan persediaan suku cadang dibuat suatu Key Performance Indicator (KPI) untuk fungsi persediaan ini. Adapun KPI yang dimaksud adalah nilai persediaan, level of service, stock level, turn over ratio, dan sleeping stock ratio. Key Performance Indicator (KPI) ini yang dibuat sebagai acuan dalam melihat kinerja persediaan dalam hal menyediakan suku cadang dalam pemeliharaan. KPI ini merupakan suatu parameter untuk melihat keberhasilan sistem CMMS terhadap pemeliharaan. 


\subsection{Pengolahan data}

Dari data-data yang telah dikumpulkan, maka dilakukan pengolahan data. Adapun pengolahan datanya adalah sebagai berikut :

1. Nilai persediaan

Nilai persediaan merupakan salah satu parameter dalam menilai kinerja persediaan. Nilai persediaan yang optimal bisa diperoleh dengan perencanaan pemeliharaan yang baik pula.

a. Data Nilai persediaan sebelum penerapan CMMS

Adapun data tentang nilai persediaan sebelum penerapan CMMS dapat dilihat pada Tabel 1. Adapun perhitungannya menggunakan rumus sebagai berikut:

Nilai Persediaan $=$ Jumlah suku cadang $\mathrm{x}$ Harga suku cadang per unit Tahun 2001

Untuk electrical parts $=280 \times 10000=2.800 .000$

Untuk mechanical parts $=2276 \times 10000=22.760 .000$

Untuk general parts $=161 \times 10000=1.610 .000$

Untuk suku cadang tambahan $=1108 \times 10000=11.080 .000$

Sehingga total nilai persediaan untuk tahun 2001 adalah 38.250 .000

- Tahun $2002: 3.010 .000+21.860 .000+1.790 .000+9.540 .000=36.200 .000$

- Tahun $2003: 3.970 .000+19.530 .000+1.850 .000+8.170 .000=33.520 .000$

- Tahun $2004: 2.740 .000+20.290 .000+970.000+7.190 .000=31.190 .000$

Tabel 1. Nilai Persediaan Sebelum Penerapan CMMS

\begin{tabular}{|c|c|c|c|c|c|}
\hline Tahun & Electrical & Mechanical & General & Tambahan & Total \\
\hline 2001 & $2,800,000.00$ & $22,760,000.00$ & $1,610,000.00$ & $11,080,000.00$ & $38,250,000.00$ \\
\hline 2002 & $3,010,000.00$ & $21,860,000.00$ & $1,790,000.00$ & $9,540,000.00$ & $36,200,000.00$ \\
\hline 2003 & $3,970,000.00$ & $19,530,000.00$ & $1,850,000.00$ & $8,170,000.00$ & $33,520,000.00$ \\
\hline 2004 & $2,740,000.00$ & $20,290,000.00$ & $970,000.00$ & $7,190,000.00$ & $31,190,000.00$ \\
\hline \multicolumn{5}{|c|}{ Jumlah } & $139,160,000.00$ \\
\hline \multicolumn{5}{|c|}{ Rata-rata } & $34,790,000.00$ \\
\hline
\end{tabular}

b. Data Nilai persediaan setelah penerapan CMMS

Adapun data tentang nilai persediaan setelah penerapan CMMS dapat dilihat pada Tabel 2.

Adapun perhitungannya menggunakan rumus sebagai berikut :

Nilai Persediaan $=$ Jumlah suku cadang $\mathrm{x}$ Harga suku cadang per unit

- Tahun 2005

Untuk electrical parts $=235 \times 10000=2.350 .000$

Untuk mechanical parts $=1714 \times 10000=17.140 .000$

Untuk general parts $=90 \times 10000=900.000$

Untuk tambahan suku cadang $=780 \times 10000=7.800 .000$

Sehingga total nilai persediaan untuk tahun 2005 adalah 21.170 .000

- Tahun $2006: 2.510 .000+15.480 .000+780.000+653.000=19.423 .000$

- Tahun $2007: 2.240 .000+15.880 .000+620.000+648.000=19.388 .000$

- Tahun $2008: 2.170 .000+15.250 .000+530.000+595.000=18.545 .000$

Tabel 2. Nilai Persediaan Setelah Penerapan CMMS

\begin{tabular}{|c|c|c|c|c|c|}
\hline Tahun & Electrical & Mechanical & General & Tambahan & Total \\
\hline 2005 & $2,350,000.00$ & $17,140,000.00$ & $900,000.00$ & $780,000.00$ & $21,170,000.00$ \\
\hline 2006 & $2,510,000.00$ & $15,480,000.00$ & $780,000.00$ & $653,000.00$ & $19,423,000.00$ \\
\hline 2007 & $2,240,000.00$ & $15,880,000.00$ & $620,000.00$ & $648,000.00$ & $19,388,000.00$ \\
\hline 2008 & $2,170,000.00$ & $15,250,000.00$ & $530,000.00$ & $595,000.00$ & $18,545,000.00$ \\
\hline \multicolumn{5}{|c|}{ Jumlah } & $78,526,000.00$ \\
\hline \multicolumn{5}{|c|}{ Rata-rata } & $19,632,000.00$ \\
\hline
\end{tabular}

1. Perhitungan LOS (Level Of Service)

Level Of Service adalah perhitungan untuk mengetahui kemampuan gudang dalam menyediakan kebutuhan suku cadang untuk pelaksanaan MRO. Berikut ini adalah perhitungan untuk mengetahui nilai level of service : 
a. Nilai LOS sebelum penerapan CMMS

$C p=\underline{\text { konsumsi untuk item } p}$

Konsumsi total

Tingkat konsumsi dihasilkan dari jumlah persediaan komponen suku cadang dalam satu tahun dibagi total jumlah persediaan suku cadang yang terpenuhi ditahun pertama.

i. Tahun 2001:

$$
\begin{aligned}
& \text { Untuk electrical parts }=\frac{280}{2717}=0.103 \\
& \text { Untuk mechanical parts }=\frac{2276}{2717}=0.837 \\
& \text { Untuk general parts }=\frac{161}{2717}=0.059
\end{aligned}
$$

Sehingga total level of service tahun 2001 untuk konsumsi per komponen suku cadang adalah 0.999 .

i. Tahun $2002: 0.113+0.819+0.067=0.999$

ii. Tahun $2003: 0.156+0.770+0.072=0.999$

iii. Tahun $2004: 0.114+0.845+0.04=0.999$

Tabel 3. Hasil Perhitungan nilai $\mathrm{Cp}$ sebelum Penerapan CMMS

\begin{tabular}{|c|c|c|c|c|}
\hline Tahun & Electrical Pats & Mechanical Parts & General Parts & Total Cp (\%) \\
\hline 2001 & 0.103 & 0.837 & 0.059 & 0.999 \\
\hline 2002 & 0.113 & 0.819 & 0.067 & 0.999 \\
\hline 2003 & 0.156 & 0.770 & 0.072 & 0.999 \\
\hline 2004 & 0.114 & 0.845 & 0.04 & 0.999 \\
\hline
\end{tabular}

- $F p$ adalah konsumsi total, dihasilkan dari jumlah permintaan suku cadang yang terpenuhi dibagi total permintaan suku cadang.
a) Tahun $2001=\frac{2717}{4528}=0.60$
b) Tahun $2002=\frac{2666}{4300}=0.62$
c) Tahun $2003=\frac{2535}{3961}=0.64$
d) Tahun $2004=\frac{2400}{3692}=0.65$

Tabel 4. Hasil Perhitungan nilai Fp sebelum Penerapan CMMS

\begin{tabular}{|c|c|}
\hline Tahun & $F p(\%)$ \\
\hline 2001 & 0.60 \\
\hline 2002 & 0.62 \\
\hline 2003 & 0.64 \\
\hline 2004 & 0.65 \\
\hline
\end{tabular}

Dari perhitungan diatas maka dapat dilihat nilai LOS setiap tahun sebelum penerapan CMMS pada Tabel 4.10 sebagai berikut :

Tabel 5. Hasil Perhitungan LOS sebelum Penerapan CMMS

\begin{tabular}{|c|c|c|c|}
\hline Tahun & $C p$ & $F p$ & $\begin{array}{c}\text { LOS } \\
\end{array}$ \\
\hline 2001 & 0.999 & 0.60 & 59.94 \\
\hline 2002 & 0.999 & 0.62 & 61.94 \\
\hline 2003 & 0.999 & 0.64 & 63.94 \\
\hline 2004 & 0.999 & 0.65 & $64 . .94$ \\
\hline \multicolumn{3}{|c|}{ Jumlah } & 250.76 \\
\hline Rata-rata & 62.69 \\
\hline
\end{tabular}


2. Nilai LOS Setelah Penerapan CMMS

a. $C p=\underline{\text { konsumsi untuk item } p}$

Konsumsi total

Tingkat konsumsi dihasilkan dari jumlah persediaan komponen suku cadang dalam satu tahun dibagi total jumlah persediaan suku cadang yang terpenuhi ditahun pertama.

i. Tahun 2005 :

Untuk electrical parts $=\frac{235}{2039}=0.115$

Untuk mechanical parts $=\frac{1714}{2039}=0.840$

Untuk general parts $=\frac{90}{2039}=0.044$

Sehingga total level of service tahun 2005 untuk konsumsi perkomponen suku cadang adalah 0.999 .

ii. Tahun $2006: 0.133+0.824+0.041=0.998$

iii. Tahun $2007: 0.119+0.847+0.033=0.999$

iv. Tahun $2008: 0.120+0.849+0.029=0.998$

Tabel 6. Hasil Perhitungan nilai $\mathrm{Cp}$ setelah Penerapan CMMS

\begin{tabular}{|c|c|c|c|c|}
\hline Tahun & Electrical Pats & Mechanical Parts & General Parts & Total $C p(\%)$ \\
\hline 2005 & 0.115 & 0.840 & 0.044 & 0.999 \\
\hline 2006 & 0.133 & 0.824 & 0.041 & 0.998 \\
\hline 2007 & 0.119 & 0.847 & 0.033 & 0.999 \\
\hline 2008 & 0.120 & 0.849 & 0.029 & 0.998 \\
\hline
\end{tabular}

b. Fp adalah konsumsi total, dihasilkan dari jumlah permintaan suku cadang dibagi jumlah permintaan suku cadang yang terpenuhi.

v. Tahun $2005=\frac{2039}{3089}=0.66$

vi. Tahun $2006=\frac{1877}{2760}=0.68$

vii. Tahun $2007=\frac{1874}{2716}=0.69$

viii. Tahun $2008=\frac{1795}{2564}=0.70$

Tabel 7. Hasil Perhitungan nilai Fp setelah Penerapan CMMS

\begin{tabular}{|c|c|}
\hline Tahun & Fp (\%) \\
\hline 2005 & 0.66 \\
\hline 2006 & 0.68 \\
\hline 2007 & 0.69 \\
\hline 2008 & 0.70 \\
\hline
\end{tabular}

Dari perhitungan diatas maka dapat dilihat nilai LOS setiap tahun setelah penerapan CMMS pada Tabel 4.13 sebagai berikut :

Tabel 8. Hasil Perhitungan LOS setelah Penerapan CMMS

\begin{tabular}{|c|c|c|c|}
\hline Tahun & $C p$ & $F p$ & $\begin{array}{c}\text { LOS } \\
(\Sigma(\text { CpxFp })) \times 100 \%\end{array}$ \\
\hline 2005 & 0.999 & 0.66 & 65.93 \\
\hline 2006 & 0.998 & 0.68 & 67.86 \\
\hline 2007 & 0.999 & 0.69 & 68.93 \\
\hline 2008 & 0.998 & 0.70 & 69.86 \\
\hline \multicolumn{3}{|c|}{ Jumlah } & 272.58 \\
\hline Rata-rata & & 68.15 \\
\hline
\end{tabular}


Dari perhitungan LOS sebelum dan setelah penerapan CMMS dapat dilihat perbandingan jumlah dan rata-rata, dimana besar nilai jumlah dan rata-rata setelah penerapan CMMS lebih baik. Hal ini menunjukkan dalam pelaksanaan MRO akan terlaksana tepat waktu sesuai yang direncanakan.

3. Perhitungan Stock Level

Perhitungan stock level dalam penelitian ini merupakan untuk mengetahui tingkat jumlah suku cadang yang digunakan dalam pelaksanaan MRO. Adapun perhitungannya menngunakan rumus sebagai berikut :

Dimana :

$$
\mathrm{S}=\mathrm{OH}+\mathrm{DI}-\mathrm{BO}
$$

$\mathrm{OH}=$ Jumlah permintaan suku cadang (Unit)

$D I$ = Jumlah permintaan suku cadang tambahan (Unit)

$B O=$ jumlah permintaan yang terpenuhi (Unit)

Nilai $\mathrm{S}$ untuk sebelum penerapan CMMS adalah sebagai berikut :

Tabel 9. hasil perhitungan $S$ sebelum Penerapan CMMS

\begin{tabular}{|c|c|c|c|c|}
\hline Tahun & $O H$ & $D I$ & $B O$ & $S$ \\
\hline 2001 & 4528 & 1108 & 2717 & 2919 \\
\hline 2002 & 4300 & 954 & 2666 & 2588 \\
\hline 2003 & 3961 & 817 & 2535 & 2243 \\
\hline 2004 & 3692 & 719 & 2400 & 2011 \\
\hline \multicolumn{5}{|c|}{ Jumlah } \\
\hline \multicolumn{4}{|c|}{ Rata-rata } & 2461 \\
\hline
\end{tabular}

Nilai S untuk setelah penerapan CMMS adalah sebagai berikut :

Tabel 10. hasil perhitungan $S$ setelah Penerapan CMMS

\begin{tabular}{|c|c|c|c|c|}
\hline Tahun & $\mathrm{OH}$ & $D I$ & $B O$ & $S$ \\
\hline 2005 & 3089 & 780 & 2039 & 1830 \\
\hline 2006 & 2760 & 653 & 1877 & 1536 \\
\hline 2007 & 2716 & 648 & 1874 & 1490 \\
\hline 2008 & 2564 & 595 & 1795 & 1364 \\
\hline \multicolumn{5}{|c|}{ Jumlah } \\
\hline
\end{tabular}

Dilihat dari perhitungan diatas, maka pelayanan terhadap pelaksanaan MRO yang diterapkan setelah penerapan CMMS besar nilai jumlah dan rata-ratanya semakin kecil itu berarti dalam pengendalian jumlah permintaan perbaikan setelah penerapan CMMS semakin baik dibandingkan dengan sebelum penerapan CMMS.

4. Turn Over Ratio

Turn Over Ratio merupakan salah satu parameter kinerja persediaan yang digunakan untuk menilai jumlah nilai persediaan yang dikeluarkan dari gudang dibandingkan dengan nilai total persediaan.

a. Data turn over ratio sebelum penerapan CMMS

Berikut ini merupakan contoh perhitungan untuk mengetahui persentasenya yaitu :

Turn Over Ratio = Total Biaya Yang dikeluarkan Gudang $\times 100 \%$

$$
\text { Total Nilai Persediaan }
$$

a) Untuk tahun $2001=\frac{29,452,500}{38,250,000} \times 100 \%=77 \%$

b) Untuk tahun $2002=\frac{28,236,000}{36,200,000} \times 100 \%=78 \%$

c) Untuk tahun $2003=\frac{26,816,000}{33,520,000} \times 100 \%=80 \%$

d) Untuk tahun $2004=\frac{25,887,700}{31,190,000} \times 100 \%=83 \%$ 
Adapun hasil perhitungan persentase turn over ratio selengkapnya sebelum penerapan CMMS dapat dilihat pada Tabel 11.

Tabel 11. Turn Over Ratio Sebelum Penerapan CMMS

\begin{tabular}{|c|c|}
\hline Tahun & $\begin{array}{c}\text { Turn Over } \\
\text { Ratio }\end{array}$ \\
\hline 2001 & 77 \\
\hline 2002 & 78 \\
\hline 2003 & 80 \\
\hline 2004 & 83 \\
\hline$\Sigma$ & 318 \\
\hline$x$ & 79.5 \\
\hline
\end{tabular}

b. Data turn over ratio setelah penerapan CMMS

Berikut ini merupakan contoh perhitungan untuk mengetahui persentasenya yaitu :

a) Tahun $2005=\frac{17,782,000}{21,170,000} \times 100 \%=84 \%$

b) Tahun $2006=\frac{16,703,780}{19,423,000} \times 100 \%=86 \%$

c) Tahun $2007=\frac{17,061,440}{19,388,000} \times 100 \%=88 \%$

d) Tahun $2008=\frac{17,617,750}{18,545,000} \times 100 \%=95 \%$

Adapun hasil perhitungan persentase turn over ratio selengkapnya setelah penerapan CMMS dapat dilihat pada Tabel 12.

Tabel 12. Turn Over Ratio Setelah Penerapan CMMS

\begin{tabular}{|c|c|}
\hline Tahun & $\begin{array}{c}\text { Turn Over } \\
\text { Ratio }\end{array}$ \\
\hline 2005 & 84 \\
\hline 2006 & 86 \\
\hline 2007 & 88 \\
\hline 2008 & 95 \\
\hline$\Sigma$ & 351 \\
\hline$X$ & 87.75 \\
\hline
\end{tabular}

5. Sleeping Stock Ratio

Sleeping Stock Ratio merupakan Indikator rasio perbandingan untuk persediaan tidak aktif atau tidak terpakai.

a. Data sleeping stock ratio sebelum penerapan CMMS

Berikut ini merupakan contoh perhitungan untuk mengetahui persentasenya yaitu : Sleeping Stock Ratio = Jumlah suku cadang yang tidak aktif $\times 100 \%$ Total jumlah suku cadang
a) Tahun $2001=\frac{703}{4528} \times 100 \%=15.52 \%$
b) Tahun $2002=\frac{680}{4300} \times 100 \%=15.81 \%$
c) Tahun $2003=\frac{609}{3961} \times 100 \%=15.37 \%$
d) Tahun $2004=\frac{573}{3692} \times 100 \%=15.52 \%$ 
Adapun data tentang sleeping stock ratio sebelum penerapan CMMS dapat dilihat pada Tabel 13.

Tabel 13. Sleeping Stock Ratio Sebelum Penerapan CMMS

\begin{tabular}{|c|c|}
\hline Tahun & $\begin{array}{c}\text { Sleeping } \\
\text { Stock Ratio }\end{array}$ \\
\hline 2001 & 15.52 \\
\hline 2002 & 15.81 \\
\hline 2003 & 15.37 \\
\hline 2004 & 15.52 \\
\hline$\sum$ & 62.22 \\
\hline $\mathrm{X}$ & 15.56 \\
\hline
\end{tabular}

b. Data sleeping stock ratio setelah penerapan CMMS

Berikut ini merupakan contoh perhitungan untuk mengetahui persentasenya yaitu :
a) Tahun $2005=\frac{270}{3089} \times 100 \%=8.74 \%$
b) Tahun $2006=\frac{230}{2760} \times 100 \%=8.33 \%$
c) Tahun $2007=\frac{194}{2716} \times 100 \%=7.14 \%$
d) Tahun $2008=\frac{174}{2564} \times 100 \%=6.79 \%$

Adapun data tentang sleeping stock ratio setelah penerapan CMMS dapat dilihat pada Tabel 14.

Tabel 14. Sleeping stock ratio Setelah Penerapan CMMS

\begin{tabular}{|c|c|}
\hline Tahun & $\begin{array}{c}\text { Sleeping } \\
\text { Stock Ratio }\end{array}$ \\
\hline 2005 & 8.74 \\
\hline 2006 & 8.33 \\
\hline 2007 & 7.14 \\
\hline 2008 & 6.79 \\
\hline$\Sigma$ & 31 \\
\hline $\mathrm{x}$ & 7.75 \\
\hline
\end{tabular}

6. Key Performance Indicator

Key Performance Indicator merupakan perbandingan kondisi sebelum penerapan CMMS dengan setelah penerapan CMMS. Adapun hasil selengkapnya dapat dilihat pada Tabel 15.

Tabel 15. Key performance indicator

\begin{tabular}{|c|c|c|c|}
\hline No & Key performance indicator & $\begin{array}{c}\text { Sebelum penerapan } \\
\text { CMMS }\end{array}$ & $\begin{array}{c}\text { Setelah penerapan } \\
\text { CMMS }\end{array}$ \\
\hline 1 & Nilai Persediaan & $34,790,000.00$ & $19,632,000.00$ \\
\hline 2 & Level of Service & 62.69 & 68.15 \\
\hline 3 & Stock Level & 2440 & 1555 \\
\hline 4 & Turn Over Ratio & 79.5 & 87.75 \\
\hline 5 & Sleeping Stock Ratio & 15.56 & 7.75 \\
\hline
\end{tabular}

7. Analisis Hasil

1. Nilai key performance indicator

Dari hasil pengolahan data diatas diperoleh nilai untuk key performance indicator adalah sebagai berikut :

a. Untuk nilai persediaan pada kondisi sebelum penerapan CMMS adalah sebesar $\$ 34,790,000.00$ dan untuk kondisi setelah penerapan CMMS adalah sebesar $\$ 19,632,000.00$ sehingga dapat dilihat penurunan nilai persediaan sebesar $\$ 15,158,000.00$ dimana biaya yang dikeluarkan lebih sedikit dari biaya sebelumnya.

b. Untuk Level Of Service pada kondisi sebelum penerapan CMMS adalah sebesar $62.69 \%$ dan untuk kondisi setelah penerapan CMMS adalah sebesar $68.15 \%$ sehingga untuk level 
of service mengalami peningkatan sebesar $5.46 \%$ yang berarti kemampuan dalam memenuhi kebutuhan suku cadang dalam pelaksanaan MRO akan lebih cepat terpenuhi dari sebelumnya.

c. Untuk Stock Level pada kondisi sebelum penerapan CMMS adalah sebesar 2440 unit dan untuk kondisi setelah penerapan CMMS adalah sebesar 1555 unit yang berarti tingkat pemakaian suku cadang lebih sedikit.

d. Untuk turn over ratio pada kondisi sebelum penerapan CMMS adalah sebesar $79.5 \%$ dan untuk kondisi setelah penerapan CMMS adalah sebesar $87.75 \%$ sehingga turn over ratio mengalami peningkatan sebesar $8.25 \%$ yang berarti perputaran pemakaian suku cadang yang berada digudang lebih cepat dibandingkan dengan sebelum penerapan CMMS.

e. Untuk sleeping stock ratio pada kondisi sebelum penerapan CMMS adalah sebesar $15.56 \%$ dan untuk kondisi setelah penerapan CMMS adalah sebesar $7.75 \%$ sehingga sleeping stock ratio mengalami penurunan sebesar $7.81 \%$ yang berarti suku cadang yang tidak terpakai semakin kecil dibandingkan dengan sebelum penerapan CMMS.

Sehingga dengan adanya peningkatan dan penurunan terhadap key performance indicator, sangat membantu departemen management terutama dalam melaksanakan kegiatan MRO dengan tepat waktu tanpa mengganggu jalannya proses produksi.

2. Analisis Faktor-faktor Penurunan Nilai Persediaan

Dalam menganalisis penyebab terjadinya penurunan nilai persediaan barang MRO dilakukan dengan cara menentukan faktor-faktor apa saja yang paling berpengaruh. Tabel 16 . adalah sebagai alat analisis dalam mencari tahu penyebab turunnya nilai persediaan barang MRO. Fungsi persediaan dan indikator kinerja untuk persediaan adalah turunnya nilai persediaan barang MRO. Untuk itu perlu diketahui penyebab terjadi penurunan dalam nilai persediaan untuk melakukan kegiatan MRO.

Tabel ini akan digunakan untuk menjawab permasalahan yang teridentifikasi pada penelitian ini. Adapun hasil faktor-faktor penyebab penurunan nilai persediaan suku cadang untuk kegiatan MRO ini dapat dilihat pada Tabel 16.

Tabel 16. Faktor-faktor Penyebab Penurunan Nilai Persediaan

\begin{tabular}{|c|c|c|}
\hline No & Faktor- faktor & Tujuan atau sasaran \\
\hline 1 & $\begin{array}{l}\text { Inventory } \\
\text { - Sleeping stock ratio } \\
\text { - Cataloguing } \\
\text { - Turn over ratio } \\
\text { - Level of service }\end{array}$ & $\begin{array}{l}\text { Ketersediaan suku cadang yang } \\
\text { ada digudang semakin cepat }\end{array}$ \\
\hline 2 & $\begin{array}{l}\text { Maintenance } \\
\text { - Preventive maintenance } \\
\text { - Work order } \\
\text { - Management } \\
\text { - Planning } \\
\text { - Scheduling }\end{array}$ & $\begin{array}{c}\text { Perencanaan dan penjadwalan } \\
\text { pemeliharaan agar berjalan dengan } \\
\text { tepat waktu }\end{array}$ \\
\hline 3 & $\begin{array}{l}\text { Procurement } \\
\text { - Lead Time } \\
\text { - Vendor performance } \\
\text { - Inventory delay }\end{array}$ & $\begin{array}{l}\text { Waktu untuk menyediakan suku } \\
\text { cadang semakin pendek }\end{array}$ \\
\hline 4 & $\begin{array}{l}\text { Human resources } \\
\text { - Skill } \\
\text { - Ability } \\
\text { - Motivation } \\
\text { - Leadership }\end{array}$ & $\begin{array}{l}\text { Menjalankan proses dan prosedur } \\
\text { pemeliharaan dengan baik }\end{array}$ \\
\hline
\end{tabular}

Dari tabel faktor-faktor penyebab penurunan nilai persediaan suku cadang untuk kegiatan MRO diatas diperoleh bahwa penyebab adanya optimalisasi kinerja persediaan ada empat penyebab utama yaitu sisi persediaan, pengadaan, pemeliharaan dan sumber daya manusia. CMMS sendiri merupakan integrasi dari persediaan, pengadaan, dan pemeliharaan dan didukung sepenuhnya oleh sumber daya manusia yang mampu melaksanakan fungsi-fungsi di CMMS. Keterkaitan ketiga fungsi tersebut sangat menentukan dalam penurunan nilai 
persediaan. Penyebab utama tersebut dianalisis dengan menggunakan penyebab-penyebab lanjutan.

a. Persediaan (Inventory)

Dari sisi persediaan dengan mengacu kepada landasan teori untuk taktikal indikator kinerja dapat diperoleh empat bagian yang secara langsung berpengaruh kepada turunnya nilai persediaan. Adapun keempat indikator tersebut adalah:

i. Kataloging (Cataloguing)

Sejak penerapan sistem CMMS pada tahun 2005 dibentuk tim kataloging yang melakukan pengkategorian dan standarisasi terhadap seluruh persediaan suku cadang di PT.INALUM. menurut perhitungan telah terjadi penghematan dikarenakan adanya pengurangan yang signifikan pada jumlah suku cadang yang terduplikasi, tidak terpakai lagi, serta adanya barang yang bisa dipakai secara bersama-sama.

ii. Level Of Service

Tingkat pelayanan terhadap permintaan suku cadang oleh bagian pemeliharaan juga menentukan tingkat nilai persediaan. Karena apabila tingkat pelayanan ini bisa berada diantara 95\% - 97\% akan memberikan jaminan ketersediaan suku cadang untuk setiap permintaan barang dari pemeliharaan. Untuk PT.INALUM sendiri rata-rata tingkat pelayanan ini masih dikisaran $68 \%$ hal ini sangat dipengaruhi oleh terlambatnya proses pemasukan data dan proses data sehingga data yang disajikan menjadi kurang tepat. Hal ini diakibatkan adanya keterlambatan posting transaksi pada sistem. Adanya perbaikan dalam sistem permintaan dan proses pencatatan transaksi akan memberikan gambaran yang lebih jelas terhadap proses ini. Karena secara aktual masalahnya adalah adanya perubahan jadwal pemeliharaan secara aktual tetapi proses permintaan barang MRO masih tetap pada jadwal semula hal inilah yang mengakibatkan kurang tercapainya target level of service ini.

iii. Turn Over Ratio

Perputaran pemakaian persediaan MRO diharapkan semakin tinggi sehingga lama persediaan yang tersimpan di gudang semakin pendek sehingga secara langsung memberikan pengaruh terhadap penurunan nilai persediaan. Dalam hal ini sesuai dengan data yang diperoleh dari bagian IIT (Inalum Information Technology) rata-rata tahunan setelah penerapan sistem ini adalah 87.75 apabila dibandigkan dengan tahun sebelum penerapan sistem ini yang hanya 79.5 maka sistem ini sangat memberikan pengaruh terhadap turunnya nilai persediaan.

iv. Sleeping Stock Ratio

Asset yang dikatakan tidur adalah aset yang tidak dipakai/ tidak aktif, hal ini menjadikan kontrol terhadap persediaan semakin ketat. Melalui Tabel 4.20 key performance indicator untuk sleeping stock ratio mengalami penurunan sebesar $7.81 \%$. Dari $15.56 \%$ menjadi $7.75 \%$. Dalam hal ini penting menjadi perhatian yaitu asset tidak aktif, tidak semuanya bisa dijual ada beberapa persediaan MRO yang sifatnya sebagai persediaan cadangan (safety stock) yang memang penggunaannya hanya kalau terjadi kegagalan pada peralatan tersebut, jenis MRO yang seperti ini banyak sekali ditemukan pada jenis persediaan elektrik.

b. Pemeliharaan (Maintenance)

Ada empat penyebab dalam pemeliharaan yang memberikan kontribusi terhadap penurunan nilai persediaan yaitu penerapan PM, W/O manajemen, perencanaan, dan penjadwalan. Pemeliharaan merupakan inti dari sistem ini dan menurut metode INRIM (Industrial Rapid Implementation Methodology) dengan penerapan fungsi pemeliharaan sesuai dengan proses dan prosedur akan mempengaruhi nilai persediaan. Hal ini dikarenakan semakin terjadwalnya pemakaian persediaan MRO sehingga proses penyimpanan bisa lebih diperpendek dan bisa dilakukan perencanaan untuk jangka panjang maupun jangka pendek.

c. Pengadaan (Procurement)

Dari gambar 6.1 pengadaan didapatkan ada tiga penyebab yang memberikan kontribusi terhadap turunnya nilai persediaan yaitu kinerja vendor/supplier, lead time, dan proses pemilahan vendor/supplier. Kinerja dari pemasok dan pemilahaan pemasok sangat menentukan kemampuan dalam perencanaan pengadaan. Keberadaan pemasok pada saat ini tidak hanya sebagai pemasok apabila dibutuhkan, keberadaan mereka harus tetap menjadi bagian dari proses pengadaan barang MRO. Hal ini dikarenakan semakin baik manajemen pemasok semakin pendek waktu yang dibutuhkan mereka untuk pengiriman barang MRO dan semakin 
kecil kesalahan dalam pengiriman barang MRO tersebut. Sehingga waktu penyimpanan barang MRO semakin bisa diperpendek karena kemampuan pemasok yang semakin handal.

Dalam proses pengadaan selama ini ada kesan adanya proses persetujuan yang lama sekali sebelum penerapan sistem ini. Sehingga kekhawatiran ini membuat proses pengadaan sering sekali mengedepankan faktor keamanan untuk adanya barang MRO yang berlebih untuk mengatasi apabila terjadi proses persetujuan yang lama supaya tidak terjadi gangguan dalam proses pemeliharaan. Tetapi setelah penerapan sistem ini proses persetujuan semakin diperpendek. Dimana dengan sistem ini transparansi (keterbukaan) akan informasi tentang proses pengadaan semakin jelas, sehingga seluruh proses bisa di kontrol di setiap level yang ada di dalam proses tersebut.

d. Sumber Daya Manusia (Human Resources)

Peranan kemampuan sumber daya manusia sangat menentukan sukses tidaknya penerapan CMMS, hal ini dibuktikan dari adanya kontribusi sumber daya manusia dalam menurunkan nilai persediaan MRO. Dalam penerapan CMMS untuk karyawan dilakukan pelatihan intensif, workshop, adanya core team yang terus mengawasi jalannya penerapan dan manajemen yang mendukung secara penuh akan penerapan CMMS. Pelatihan tidak hanya dilakukan oleh individu yang berkaitan langsung dengan sistem ini tetapi juga pelatihan kepada seluruh karyawan agar tersosialisasi dengan baik.

Dari sisi manajemen keputusan untuk menggunakan CMMS ini menjadi isu bersama sehingga para pimpinan puncak senantiasa mengawasi jalannya penerapan CMMS. Pengawasan ini dijembatani oleh core team untuk memastikan proses dan prosedur dijalankan sesuai dengan metode yang telah didefinisikan bersama dan mencapai tujuan utama dari bisnis ini yaitu meningkatkan nilai keuntungan.

\section{KESIMPULAN DAN SARAN}

Berdasarkan penelitian yang dilakukan, maka dapat ditarik kesimpulan bahwa :

1. Dengan melihat perbandingan dari sebelum dan setelah penerapan CMMS pada tabel key performance indicator, terlihat bahwa adanya perbaikan dalam setiap parameter, yaitu nilai persediaan sebelum penerapan CMMS sebesar $\$ 34,790,000.00$ bila dibandingkan dengan setelah penerapan nilai persediaan turun menjadi $\$ 19,632,000.00$. Persentase level of service yang sebelumnya $62.69 \%$ meningkat menjadi $68.15 \%$. Stock level yang sebelum penerapan menggunakan 2440 unit suku cadang turun menjadi 1555 unit suku cadang setelah penerapan CMMS. Persentase turn over ratio yang sebelumnya $79.50 \%$ meningkat menjadi $87.75 \%$. Dan sleeping stock ratio yang sebelumnya $15.56 \%$ turun menjadi $7.75 \%$.

2. Faktor-faktor yang mempengaruhi persediaan suku cadang antara lain :
a. Persediaan (Inventory)
Dimana dalam persediaan ini meliputi :
- kataloging (cataloguing)
- Level of service
- Turn Over Ratio
- Sleeping stock ratio
b. Pemeliharaan (maintenance)
c. Pengadaan (Procurement)
d. Sumber daya manusia (Human Resources)
Berdasarkan penelitian yang dilakukan, maka saran yang diberikan bahwa :

1. Perlu dilakukan perhitungan seberapa besar pengaruh penerapan CMMS ini terhadap kinerja pemeliharaan, pengadaan dan karyawan.

2. Setiap adanya perubahan jadwal pemeliharaan jadwal akan kebutuhan material juga harus disesuaikan agar target level of service dapat tercapai.

3. Level of service harus terus ditingkatkan untuk mencapai $95 \%-97 \%$ sesuai dengan ratarata pada dunia industri. 
DAFTAR PUSTAKA

Atmosoeprapto, K, Menuju SDM Berdaya - Dengan Kepemimpinan Efektif dan Manajemen Efisien, PT. Elex Media Komputindo, Jakarta, 2002.

Jordan, T, "Management of Asset Performance Audit: PT. Indonesia Asahan Alumunium", Guidance for AVANTIS Implementation, Invensys Avantis Business Consultant, 2004.

Prawirosentono, S, Kebijakan Kinerja Karyawan - Kiat Membangun Organisasi Kompetitif Menjelang Perdagangan Bebas Dunia, BPFE, Jogjakarta, 1999.

Santoso, IB., "Bagaimana Peningkatan Kinerja Maintenance Dapat Menjadi Sebuah Penghematan Biaya Yang Besar", Maintenance Mesin Industri, Volume 2, Edisi 1, April - Juli 2006. 